Word count: $8396+1752$ (references)

\title{
Environmental design guidelines for Digital Fabrication
}

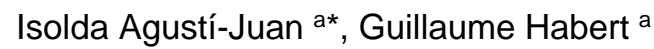

a Chair of Sustainable Construction, IBI, ETH Zürich, Stefano-Franscini-Platz 5, 8093 Zürich, Switzerland.

* Corresponding author. E-mail address: agusti@ibi.baug.ethz.ch (Isolda Agustí-Juan).

\section{Abstract}

Digital fabrication represents an innovative technology with the potential of expanding the boundaries of architecture. The potential to fabricate elements directly from design information is transforming many design and production disciplines. In particular, 3D printing has become the key of modern product development. As the use of additive manufacturing grows, research into large-scale processes is beginning to reveal potential applications in construction.

The combined methods of computational design and robotic fabrication have the well-demonstrated potential to create formal and structural advances in architecture. However, their potential contribution to the improvement of sustainability in construction must be evaluated. In this study, we identified environmental guidelines to be considered during the design of digitally fabricated architecture. The key parameters were extracted from the Life Cycle Assessment (LCA) of three case studies.

The environmental assessment performed indicated that the relative sustainability of the projects depended primarily on the building material production. Specifically, the impact of digital fabrication processes was negligible compared to the materials manufacturing process. Furthermore, the study highlighted the opportunities of integrating additional functions in structural elements with digital fabrication to reduce the overall environmental impact of these multi-functional elements. Finally, the analysis proved the potential of digital fabrication to reduce the amount of highly industrialized materials in a project, which are associated with high environmental impacts.

Keywords. Digital fabrication, LCA, environment, construction, sustainability.

\section{Introduction}

The construction sector is a highly active industry, responsible for $40 \%$ of global energy consumption, $38 \%$ of global greenhouse gas emissions, $12 \%$ of global potable water use, and $40 \%$ of solid waste generation in developed countries. Although it is a large contributor to environmental impacts, the buildings sector has a high potential to reduce emission (UNEP, 2012). Today's increasing concerns about sustainability aspects in construction are inducing the emergence of innovative technologies and processes as a solution to achieve environmental improvements and to overcome the inefficiency and lack of interoperability present in the sector. Digital fabrication processes have the potential to expand 
the boundaries of architectural design and construction.

Gershenfeld (2012) introduced the term "Digital Fabrication" for processes that use computer-controlled tools that are the descendants of MIT's first numerically controlled mill. However, the current digital tools have a broad range of applications, extending well beyond aiding the generation of planar drawings and 3D models. The potential to fabricate elements directly from design information has transformed many design and production disciplines (Dunn, 2012). Approaches to digital fabrication are typically categorized as either reductive fabrication (milling, cutting, and eroding) or additive fabrication (automated assembly, lamination, extrusions, and other forms of 3D printing). Additive manufacturing is becoming an integral part of modern product development (Hague et al., 2003), and 3D printers are currently affordable for home use (Pearce et al., 2010). As interest in additive manufacturing grows, research into large-scale processes is beginning to reveal the potential applications in construction and architecture.

The evolution of digital technologies is inseparable from the transformation of the conventional building techniques. The use of digital fabrication in architecture allows mass-production of customized complex structures, which can be developed on-site (Gramazio et al., 2014). Recent developments in3D printing of concrete elements at large-scale have shown the potential of these innovative processes to reduce the amount of material, time, waste and need for formwork in the project, which is not feasible with conventional methods of construction (Lim et al., 2012). Studies such as Lloret et al. (2014) and Hack and Lauer (2014) presented efficient robotic construction methods for the development of complex concrete structures. Other projects were related to the research on computational methods for structural optimization of complex structures, which allowed an important reduction of material (López López et al., 2014; Rippmann and Block, 2013). Moreover, approaches such as King et al. (2014) and Andreani et al. (2012) focused on the development of customized robotic methods for the assembly of material systems, in this case ceramics. Finally, a new research path is being developed, exploring additive manufacturing with the use of unconventional and locally available materials for the application in architecture (Malé-Alemany and Portell, 2014).

The combined methods of computational design and robotic fabrication have demonstrated potential to create expressive architecture, but their potential contribution to the improvement of sustainability in construction has not been the main focus of previous works. Scarce conclusive environmental assessments of large-scale digital fabrication processes are present in literature. Most published studies related to sustainability aspects of digital fabrication are focusing on small-scale additive processes (Kohtala and Hyysalo, 2015). For instance, Kreiger and Pearce (2013) and Faludi et al. (2015) focused on the life cycle assessment comparison of conventional, large-scale production and additive manufacturing or 3D printing. Both papers agreed that additive manufacturing produced less environmental impact than conventional manufacturing and resulted in a reduction of waste and the possibility of recycling. In contrast, Gebler et al. (2014) and Chen et al. (2015) assessed 3D printing from a global sustainability perspective. This research associated 3D printing technologies with a strong lowering of costs and energy use, decreasing resource demands and environmental emissions over the life cycle of a product. The challenge of full-scale architectural additive fabrication is that it is inefficient and illogical to simply "scale up" 3D printing. 
Research into the environmental benefits of digital fabrication in architecture and construction needs to be performed while it is still an experimental technology so adjustments can be made at an early stage. In the last few years, several published studies have addressed sustainability aspects in construction. Specifically, the Life cycle assessment (LCA) framework has become an important method to assess the potential environmental impacts over the life cycle of construction materials and buildings (Ortiz et al., 2009). Furthermore, LCA methodology is nowadays an important decision support tool to select appropriate technical solutions and materials to reduce environmental impacts (Ingrao et al., 2016). Energy regulations focus principally on the optimization of the energy performance in buildings during the operation phase (European Parliament and Council, 2010). As a consequence, the use of energy efficient materials and building operation technologies has increased the contribution of embodied energy in buildings (Passer et al., 2012). A solution may be the application of LCA during early stages of the project, in order to consider environmental impacts together with formal and technical aspects during the architectural design. Nevertheless, LCA is usually applied after the design process due to the complexity of the method and the need of detailed information. But by then, the results are difficult to implement because of the elevate costs associated (Hollberg and Ruth, 2016).

Digitally fabricated architecture is planned, assessed, and optimized during the design phase, understanding construction as an integral part of design (Gramazio and Kohler, 2008). Consequently, the integration of environmental criteria needs to be done during design. With this objective, two possible approaches can be applied: simplified LCA integrated in parametric design tools and environmental guidelines based on LCA results. This study follows the second approach with the aim of establishing environmental guidelines to help designers make better-informed and more sustainable choices during the digital fabrication design process. Three case studies of additive fabrication at architectural scale are presented and evaluated with LCA method. The research focuses on the comparison of environmental impacts associated with digitally fabricated architecture and conventional construction. The results from the case studies are analysed and the key criteria to be considered during design are extracted.

\section{Methodology: Life Cycle Assessment (LCA)}

Nowadays, a great number of tools are available for environmental assessment of the built environment. The most accepted ones are using a life cycle approach for assessing environmental impacts associated with buildings and building materials (Ding, 2014). Life Cycle Assessment (LCA) is a methodology based on the international standards ISO 14040-44 for evaluating the environmental load of processes and products during their life cycle, from cradle to grave (ISO, 2006a, b). The main objectives of LCA are to help decision makers choose among different alternatives considering their environmental performance and to provide a basis for the design and improvement of a system from an environmental point of view. LCA has been used in the building sector since 1990 (Fava, 2006), and it is now a widely used methodology (Chen et al., 2010; Damineli et al., 2010; Purnell and Black, 2012).

Different tools based on the LCA method have been developed for the environmental assessment of the construction materials and buildings. According to Ortiz et al. (2009), and Cabeza et al. (2014), LCA tools can be divided in 3 levels. Level 1 includes product comparison tools such as Gabi, SimaPro, 
TEAM, EDIP and LCAiT. A second level includes whole building design decision support tools like ATHENA, BEE, LISA, Ecoquantum and Envest. Finally, level 3 includes environmental rating systems for the whole building assessment, some of the most well-known in Europe are LEED, BREEAM and DGNB. Additionally, Ortiz et al. (2009) established a second classification based the application of LCA methodology in the construction sector. A first category for building material and component combinations, and a second category of tools applied to the full building life cycle. The first category includes environmental product declarations (EPD), which are largely used in the construction field. EPDs provide quantitative environmental data based on the LCA of the products, which can be used to make reliable comparisons between building materials (Bovea et al., 2014).

In the last few years, the development of Building Information Modelling (BIM) in the construction sector has led to the development of solutions for the integration of environmental evaluations in building design (Azhar and Brown, 2009; Wong and Fan, 2013). BIM is based on a virtual 3D model of the building as a shared database containing all information related to the project (Czmoch and Pękala, 2014). BIM plugins such as Tally (Bates et al., 2013) have been developed for a faster LCA of a complete construction project. Simultaneously, the evolution of modern architecture towards an increased formal complexity has incremented the use of Computer Aided Architecture Design (CAAD) tools, such as Rhino + Grasshopper. Parametric design tools, which are used in digital fabrication, have a high formal flexibility and data uncertainty during design, therefore, they require alternative LCA approaches. As a result, initial studies have developed design-integrated LCA parametric tools (Hollberg and Ruth, 2016). Alternatively, a second approach consists in the elaboration of design guidelines based on LCA results. The European Commission's report "Environmental Improvement Potentials of Residential Buildings" (Nemry and Uihlein, 2008) and the Spanish guidelines on eco-design in building materials (IHOBE, 2010) are some examples of this approach. This paper focuses on this last LCA method in order to establish basic design guidelines applied to digital fabrication in architecture.

In the application of the LCA framework to digital fabrication, defining the functional unit is the most critical part. Many digitally fabricated projects present additional functions to their structural function that add difficulty to their evaluation. For instance, an emblematic project, such as the Gantenbein Vineyard Façade made by Gramazio and Kohler (Gramazio and Kohler, 2008), is not only a façade with structural properties. It interacts with the surroundings and provides additional functions, such as light and thermal and visual effects that give added value to the architecture (Moussavi et al., 2006). The difficulty of assessing these types of projects consists of finding a conventional construction system that concentrates the different functions. Therefore, for each particular project, a detailed study to tailor the functional unit is needed. In this study, the functions that are assessed are the performance functions, such as acoustics, insulation and lighting, which can be achieved in conventional construction through the addition of a specific material that will provide this specific function. The most difficult additional function, i.e., the aesthetics and the additional benefits of an aesthetic design, such as longer service life, will not be considered in this study because it relies on too much approximation, but all efforts will be made to keep the final aspect as similar as possible because recent studies have highlighted the potential environmental benefits of aesthetics (Nielsen and Wenzel, 2002).

From different digital fabrication projects studied, three representative digitally fabricated building 
elements were selected for the present study. Specifically, classic building elements constructed with innovative additive processes were included: a wall, a roof and a slab floor. The projects were assessed and compared with three conventional construction systems with equivalent functions. The selection of the relevant data for the life cycle inventory $(\mathrm{LCl})$ was collected from different case studies, digital fabrication literature and environmental data present in publications related to the field. Additionally, most of the data related to digital fabrication processes and technologies was collected in collaboration with the NCCR Digital Fabrication research group. The life cycle impact assessment (LCIA) was performed in the software SimaPro 7.3 using the Ecoinvent database v2.2 (Hischier et al., 2010). The method Recipe Midpoint (H) V1.06 (Goedkoop et al., 2009) was used for the assessment. Table 1 shows the selected midpoint impact categories.

\begin{tabular}{ll}
\hline LCIA method Recipe Midpoint $\mathbf{( H )}$ & \\
\hline Impact category & Units \\
\hline \hline Climate change & $\mathrm{kg} \mathrm{CO}$ eq. \\
\hline Ozone depletion & $\mathrm{kg} \mathrm{CFC-11} \mathrm{eq.}$ \\
\hline Human toxicity & $\mathrm{kg} \mathrm{1.4-DB} \mathrm{eq.}$ \\
\hline Terrestrial acidification & $\mathrm{kg} \mathrm{SO}$ eq. \\
\hline Freshwater eutrophication & $\mathrm{kg} \mathrm{P}$ eq. \\
\hline Terrestrial ecotoxicity & $\mathrm{kg} \mathrm{1.4-DB} \mathrm{eq.}$ \\
\hline Freshwater ecotoxicity & $\mathrm{kg} \mathrm{1.4-DB} \mathrm{eq.}$ \\
\hline Water depletion & $\mathrm{m}^{3}$ \\
\hline Metal depletion & $\mathrm{kg} \mathrm{Fe} \mathrm{eq.}$ \\
\hline Fossil depletion & $\mathrm{kg}$ oil eq. \\
\hline
\end{tabular}

Table 1. Selected midpoint impact categories from the method Recipe Midpoint (H).

\section{Case studies}

The three case studies presented below establish a comparison between three digital fabrication projects and three classic building elements with the same function. The assessment of the projects include the production of materials and construction phase, moreover, the first case study includes the use phase. The end of life is not considered, but it is discussed in the last section of the paper.

\subsection{Wall}

The digital fabrication project selected for the assessment was a self-shading brick wall modelled by computational design and constructed by an in-situ robotic arm. Research in geometry and performance innovation in ceramic building systems through design robotics performed by $\mathrm{S}$. Andreani and $\mathrm{M}$. Bechthold from Harvard University was taken as a reference. The study investigates masscustomization methods for the creation of dynamic ornamental effects and the reduction of thermal gain on façades with brick cladding. Computational design methods and robotic fabrication technologies are integrated with traditional methods of masonry. Custom brick shapes are used to optimize assembly configuration, creating shading on the wall surface that contributes to the improved thermal performance 
of the façade (Andreani and Bechthold, 2014).

\subsubsection{System boundaries}

In this case study, we assessed the environmental impacts associated with raw material extraction, digital technologies and building materials production, robotic assembly and operation energy of the wall (EN 15978 modules: A1-A3, A5, B6). The self-shading project studies the potential of digitally fabricated geometric articulations to reduce the heat gain of a façade during operation; therefore, the use phase was included in the assessment. The location of the project is the United States, hence the LCl includes US data from Ecoinvent database.

\subsubsection{Functional unit}

The functional unit of the case study was $1 \mathrm{~m}^{2}$ brick façade with a specific structural and thermal performance. In the current evaluation, two systems were compared: a $1 \mathrm{~m}^{2}$ self-shading brick wall constructed with digital fabrication techniques and $1 \mathrm{~m}^{2}$ of a wall system with a similar brick masonry aspect and the same structural and thermal performance. For the functional unit definition, the physical performance (structural and thermal) and the aspects of the wall systems were considered. The brick aspects are a simple way to consider the aesthetics of the wall.

\subsubsection{Data collection}

The basic material composition of the self-shading wall was plain clay bricks with $5 \times 11 \times 14 \mathrm{~cm}$ dimensions assembled leaving $1 \mathrm{~cm}$ of cement mortar joints. In total, 111 bricks were included in $1 \mathrm{~m}^{2}$ of the wall, with an average density of $2,300 \mathrm{~kg} / \mathrm{m}^{3}$. Additionally, $10 \%$ of the mass of brick was included for the creation of the self-shading effect. The remaining volume corresponded to the cement mortar, including $53 \mathrm{~kg}$ of cement with a density of $2,162 \mathrm{~kg} / \mathrm{m}^{3}$. In the conventional wall, the same type of brick was considered, with an additional insulation in the interior (see Figure 1). The calculation of the insulation thickness showed that approximately $1.5 \mathrm{~cm}$ of EPS was required to achieve the same thermal performance as the self-shading function during the use phase.
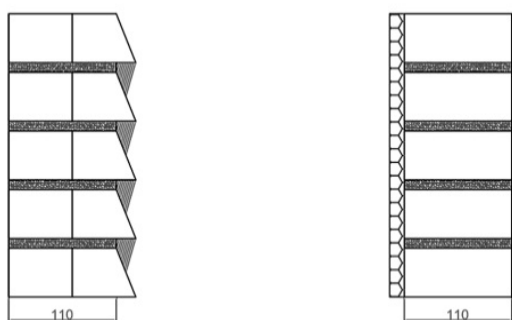

Figure 1. Self-shading brick and conventional brick with insulation wall sections.

The life cycle inventory ( $\mathrm{LCl}$ ) of the self-shading system included the embodied energy of the digital fabrication technologies. The production data of the construction robot were obtained from the prototype "In-Situ Fabricator" in collaboration with the NCCR Digital Fabrication research group. The impacts of the robot production process were studied via the mass of the composition materials, presented in Table 2. Due to the uncertainty in the service life of the construction robot, the data of 10 years was based on the service life of a mini-excavator. 


\begin{tabular}{llll}
\hline \hline Flow & Category & Unit & Amount \\
\hline \hline Steel, low-alloyed, at plant & Material & $\mathrm{kg}$ & 570.6 \\
\hline Steel, electric, un- and low-alloyed, at plant & Material & $\mathrm{kg}$ & 120.6 \\
\hline Cast iron, at plant & Material & $\mathrm{kg}$ & 119.5 \\
\hline Copper, primary, at refinery & Material & $\mathrm{kg}$ & 35.55 \\
\hline Aluminium, production mix, at plant & Material & $\mathrm{kg}$ & 37.70 \\
\hline Alkyd paint, white, 60\% in H2O, at plant & Material & $\mathrm{kg}$ & 1.65 \\
\hline Epoxy resin, liquid, at plant & Material & $\mathrm{kg}$ & 4.35 \\
\hline Polyvinylchloride, suspension polymerized, at plant & Material & $\mathrm{kg}$ & 16.41 \\
\hline Polyurethane, flexible foam, at plant & Material & $\mathrm{kg}$ & 0.31 \\
\hline Tin, at regional storage & Material & $\mathrm{kg}$ & 0.14 \\
\hline Lead, primary, at plant & Material & $\mathrm{kg}$ & 0.08 \\
\hline Nickel, 99,5\%, at plant & Material & $\mathrm{kg}$ & 0.05 \\
\hline Silver, at regional storage & Material & $\mathrm{kg}$ & 0.004 \\
\hline Gold, primary, at refinery & Material & $\mathrm{kg}$ & 0.001 \\
\hline Synthetic rubber, at plant & Material & $\mathrm{kg}$ & 40.0 \\
\hline Lubricating oil & Material & $\mathrm{kg}$ & 40.0 \\
\hline Battery, Lilo, rechargeable, prismatic, at plant & Material & $\mathrm{kg}$ & 50.0 \\
\hline
\end{tabular}

1 Table 2. Material composition and ecoinvent processes used for the construction robot (kg/unit)

3 For the data inventory of the laptop computer required, the process of a laptop computer production from the Ecoinvent database (Weidema B. P., 2013) was included. Additionally, the production of masscustomized bricks required a saw tool that attached to the robot to cut the bricks into the desired shape. For the production process of the diamond wire cutting tool, data from the composition of a $500 \mathrm{~mm}$ saw collected in literature were taken as a reference (Ioannidou et al., 2014).

The energy consumption of the robot and laptop computer (Deng et al., 2011) during construction required the addition of US electricity data from the Ecoinvent database to the $\mathrm{LCl}$. The power supply of the robot was two Li-ion rechargeable batteries with a capacity of $5.12 \mathrm{kWh}$. The construction time was calculated based on two seconds of cutting and 30 seconds of assembling per brick. Additionally, two minutes were added every 50 bricks for robot positioning. The construction of the conventional wall system involves manual labour. However, energy requirements and emissions related to human life typically are not included in environmental analysis (Zhang and Dornfeld, 2007). Table 3 presents the processes included in the $\mathrm{LCl}$ of the digitally fabricated system production.

\begin{tabular}{lll}
\hline \hline Flow & Unit & Amount \\
\hline \hline Construction robot (see Table 1) & $\mathrm{p}$ & $2.2610^{-5}$ \\
\hline Laptop computer, at plant & $\mathrm{p}$ & $7.5410^{-5}$ \\
\hline Diamond cutting tool (see supplementary information) & $\mathrm{p}$ & $1.4010^{-6}$ \\
\hline Brick, at plant & $\mathrm{kg}$ & 216.4 \\
\hline
\end{tabular}




\begin{tabular}{lll}
\hline Cement mortar, at plant & $\mathrm{kg}$ & 52.8 \\
\hline Electricity, medium voltage, at grid & $\mathrm{MJ}$ & 36.6 \\
\hline
\end{tabular}

Table 3. Life cycle inventory of the self-shading wall construction process $\left(1 \mathrm{~m}^{2}\right)$

The operation energy of the systems was calculated based on the residential cooling consumption system present in the "Life cycle assessment of residential heating and cooling systems in four regions in the United States" (Shah et al., 2008). The house model taken as a reference is located in Texas (US) due to the high effectiveness of self-shading systems in hot climates. For the energy consumption calculation, a house with $230 \mathrm{~m}^{2}$ of opaque façade and $4240 \mathrm{kWh}$ of cooling electricity consumption per year during 50 years of use was considered. From the total energy demand, only $20 \%$, corresponding to the walls heat gain, was included (Government of South Australia, 2015). Additionally, a $16 \%$ reduction of the cooling energy demand was considered in both wall systems due to the thermal effect of shading and insulation (Andreani and Bechthold, 2014). Therefore, a total operation energy of approximately $559 \mathrm{MJ}$ was added to the $\mathrm{LCl}$.

\subsection{Floor}

The second digital fabrication project selected was a fibre-reinforced concrete slab floor designed by integrating computational design and new insights from material science. Innovative computational approaches integrate structural form-finding in design, offering new possibilities for formal expression and material-reducing approaches for the construction of complex structures (Rippmann and Block, 2013). The "Rib-stiffened funicular floor system" (BLOCK research group, ETH Zurich, 2014) consists of a thin funicular vault stiffened by a system of rib walls on its extrados. The structural prototype rests on four supports completed with tension ties, which link the supports and absorb the horizontal thrusts of the funicular shell. The structural system is implemented and constructed in high-performance, selfcompacting, fibre-reinforced concrete (SCFRC), designed to work in high compression strength. SCFRC enables the casting of a $2 \mathrm{~cm}$ tick vault and ribs to resist asymmetrical loading (López López et al., 2014).

\subsubsection{System boundaries}

In this case study, we assessed the environmental impacts from the extraction of raw materials up to the construction site (EN 15978 modules: A1-A3). The concrete vault focuses on structural form-finding for resource-efficient construction. Therefore, the evaluation of this floor system was specifically focused on the design phase and material usage. The location of the project is Switzerland, hence the $\mathrm{LCl}$ includes $\mathrm{CH}$ data from Ecoinvent database.

\subsubsection{Functional unit}

The functional unit of the case study was $1 \mathrm{~m}^{2}$ of a concrete floor structure with a specific structural performance. Two systems were compared: $1 \mathrm{~m}^{2}$ of the fibre-reinforced concrete vault designed by computational design and $1 \mathrm{~m}^{2}$ of conventional reinforced concrete slab used both as the building floor 
structure. In the definition of the functional unit, functional and materiality factors were considered.

\subsubsection{Data collection}

The rib-stiffened funicular floor system has a total area of approximately $2.7 \mathrm{~m}^{2}$ and a maximum span of $2.8 \mathrm{~m}$ (see Figure 2). Four high performance steel tension ties of $\varnothing 5 \mathrm{~mm}$ are needed to counteract the vault forces on the four supports. The main composition of the vault is self-compacting, fibrereinforced concrete (SCFRC) with a density of $2,427 \mathrm{~kg} / \mathrm{m}^{3}$, designed to exhibit high compression strength. The total volume of concrete employed in the structure is $0.13 \mathrm{~m}^{3}$ (López López et al., 2014).

Table 4 shows the recipe for $1 \mathrm{~m}^{3}$ of the SCFRC compared to $1 \mathrm{~m}^{3}$ of standard concrete:

\begin{tabular}{llll}
\hline Flow & Unit & SCFRC & Standard concrete \\
\hline \hline Portland cement, strength class Z 52.5, at plant & $\mathrm{kg}$ & 923.2 & \\
\hline Portland cement, strength class Z 42.5, at plant & $\mathrm{kg}$ & & 300 \\
\hline Microsilica (see supplementary information) & $\mathrm{kg}$ & 64.6 & \\
\hline Gravel round, at mine & $\mathrm{kg}$ & $1,135.5$ & 1890 \\
\hline Tap water, at user & $\mathrm{kg}$ & 230.8 & 186 \\
\hline Plasticizer (see supplementary information) & $\mathrm{kg}$ & 21.2 & \\
\hline Steel, low-alloyed, at plant (microfibres 12 mm) & $\mathrm{kg}$ & 78.5 & \\
\hline
\end{tabular}

Table 4. Recipe SCFRC concrete adapted from López López et al. (2014) and "normal concrete, at plant" from Ecoinvent database $\left(1 \mathrm{~m}^{3}\right)$.

We compared the previous project with a bidirectional reinforced concrete slab. The conventional floor assessed had 5.5 metres of span and a total area of approximately $30 \mathrm{~m}^{2}$. The basic material composition was B500B steel reinforcement coated and C25 concrete. Considering $1 \mathrm{~m}^{2}$ of the structure, $18.5 \mathrm{~kg}$ of "steel, low-alloyed, at plant" and $0.218 \mathrm{~m}^{3}$ of "concrete, normal, at plant" were included in the $\mathrm{LCl}$ (see supplementary information).

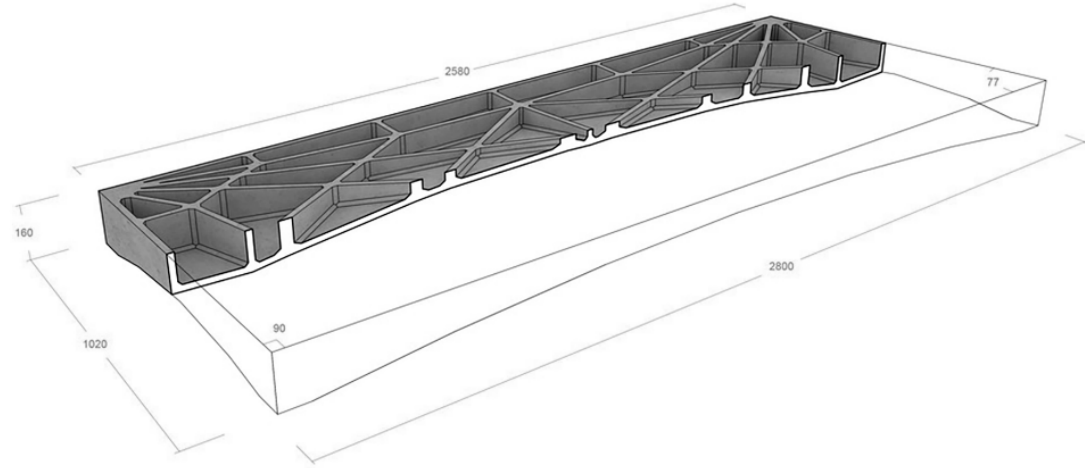

Figure 2. Perspective section of the structural prototype of the "Rib-stiffened funicular floor system"(López López et al., 2014).

\subsection{Roof}


The third digital fabrication project selected was the wooden roof of the future Arch_Tec_Lab of the Institute of Technology in Architecture (ITA). "The Sequential Roof" (Gramazio Kohler Research, ETH Zürich, 2010-2015) consists of 168 single trusses, which are woven into a 2,308 square metre freeform roof design. The structure has been constructed using digital fabrication methods, and 48624 timber slats of approximately $100-150 \mathrm{~cm}$ in length have been robotically assembled to create the large-scale load bearing structures. The project demonstrates the potential of combining digital fabrication technology applied at full architectural scale with timber as a local and natural building material. The mechanized assembly of the wood structures allows for a reduction in the construction time from manual assembly and has potential interest with regard to the use of recycling waste wood (Gramazio Kohler Research, 2014).

\subsubsection{System boundaries}

In this case study we assessed the environmental impacts associated with the extraction of raw material, digital technologies manufacturing, building materials production and the prefabrication process of the roof elements (EN 15978 modules: A1-A3, A5). The Sequential Roof project focuses on the efficiency of the construction process. Furthermore, the structure is endowed with additional functions (finishing and acoustic performance) to their main structural function, allowing the elimination of additional elements, such as hanging ceilings. For those reasons, the assessment was focused on the production phase. The location of the project is Switzerland, hence the $\mathrm{LCl}$ includes $\mathrm{CH}$ data from Ecoinvent database.

\subsubsection{Functional unit}

The functional unit of the case study was $1 \mathrm{~m}^{2}$ of the roof structure. Two systems were compared: $1 \mathrm{~m}^{2}$ of computationally designed and robotically assembled wood roof and $1 \mathrm{~m}^{2}$ of conventional wood roof structure with hanging ceiling. In the definition of the conventional functional unit, structural and functional factors (e.g., acoustic performance) as well as materiality were taken into consideration.

\subsubsection{Data collection}

"The Sequential Roof" is composed of trusses of C24 fir/spruce wood (see Figure 3). The roof has a total wood volume of $384 \mathrm{~m}^{3}$, including $70 \mathrm{~kg}$ of wood per $\mathrm{m}^{2}$. The wood sticks were robotically assembled using 815,984 nails with $90 \mathrm{~mm}$ length and ø3.4 $\mathrm{mm}$ steel nails. The digital manufacturing process of the 168 trusses was performed by a custom six-axis overhead gantry robot in the manufacturer's factory (Willmann et al., 2016). The life cycle inventory ( $\mathrm{LCl}$ ) of the digitally fabricated roof includes the embodied energy of the robotic infrastructure in factory. The material composition of two robotic arms and data from a desktop computer (Williams and Sasaki, 2003) were included in the assessment. The lifespans considered for both technologies were 10 and 5 years. Finally, the energy consumption of both technologies during 12 hours of production was included in the data inventory. The electricity data were taken from the Ecoinvent database (Weidema B. P., 2013).

The conventional roof system was composed by different elements. The basic wood structure was formed by $0.3 \times 1 \times 15 \mathrm{~m}$ Glulam spruce beams and $0.1 \times 0.22 \times 4 \mathrm{~m}$ joists. The beams were positioned with an interspace of 4 metres, and the joists were placed every 0.8 metres. The joists were connected to the beams with galvanized steel hangers with dimensions $0.1 \times 0.16 \times 0.16 \mathrm{~m}$. The wood structure was 
covered by $19 \mathrm{~mm}$ of water-proof particle board. This panel was attached to the structure with steel nails of $90 \mathrm{~mm}$ length and $\varnothing 3.4 \mathrm{~mm}$. In addition, a hanging ceiling finished the structure and protects the acoustics. The ceiling was composed of $0.6 \times 1.2 \mathrm{~m}$ laminated wood boards and a structure of galvanized steel profiles hanging from ø $\varnothing \mathrm{mm}$ steel bars. Additionally, the interior face of the ceiling contained $5 \mathrm{~cm}$ of rockwool acoustic insulation.

Details of the $\mathrm{LCl}$ are available in supplementary information.

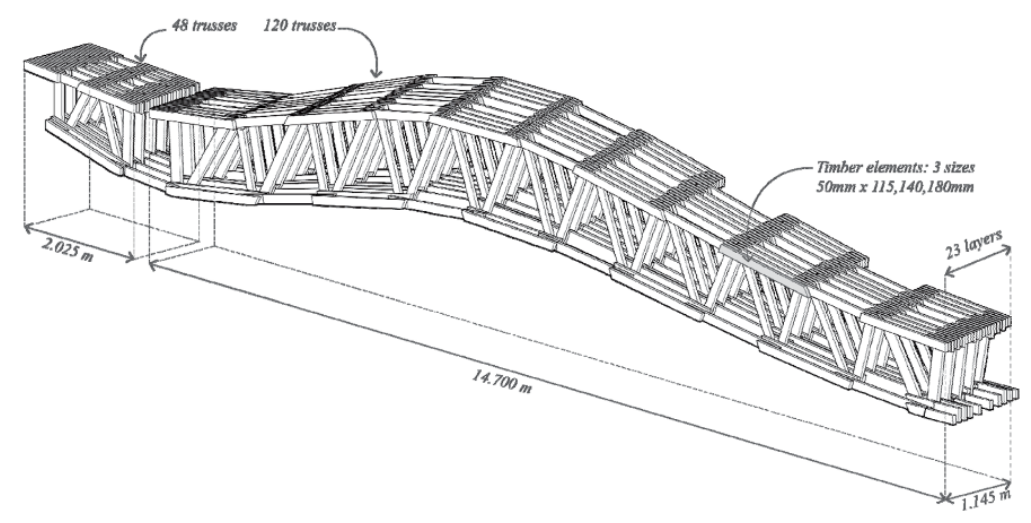

Figure 3. Section of the structural prototype of "The Sequential Roof" (Gramazio Kohler Research, ETH Zürich)

\section{Results}

The results from the analysis of the digital fabrication process and their comparison with conventional construction are detailed below. Furthermore, the optimized case studies present additional results.

\subsection{Wall}

\subsubsection{Environmental impact of the digital fabrication project}

The environmental assessment of the self-shading wall was divided into four processes: brick production, cement mortar production, digital fabrication technologies (construction robot and laptop computer) production, and electricity consumption during construction. Figure $\mathbf{4}$ graphically depicts the relative contribution of each process to the overall environmental impact of the construction of $1 \mathrm{~m}^{2}$ of self-shading wall. The highest impact of the robotically fabricated façade is attributed to brick production. The electricity consumption during the robotic construction process remains relatively high; however, this factor varies considerably depending on the method of electricity generation. Nevertheless, the relative impact of the production of digital fabrication technologies is very low in all midpoint indicators. This impact is almost $5 \%$ higher in human toxicity due to the use of lithium batteries, and it represents $10 \%$ metal depletion due to the steel composition of robots. In conclusion, the environmental assessment indicated that the relative sustainability of a self-shading façade depended primarily on the brick production process. 


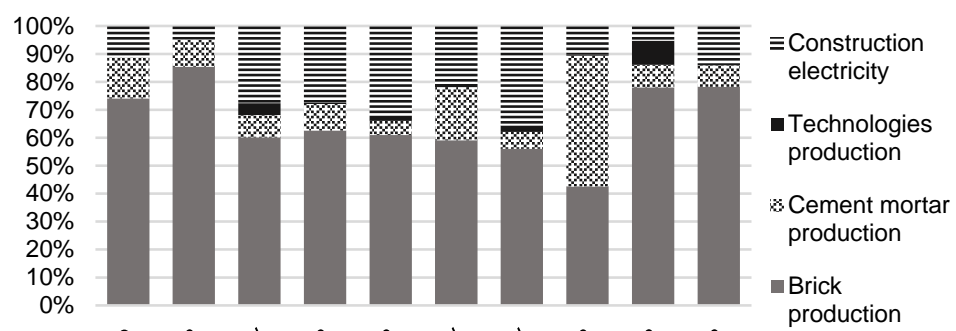

.

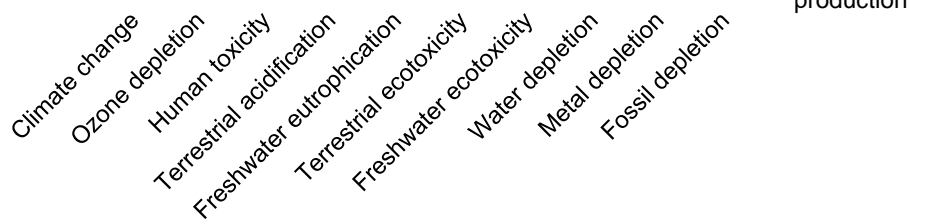

Figure 4. Relative contributions to the total environmental impact of the production of $1 \mathrm{~m}^{2}$ of self-shading wall.

\subsubsection{Comparative LCA with conventional construction}

In this section, we compared the environmental impact of digital fabrication with conventional construction. Specifically, the comparison was related to the impact of the production and operation of the two façade system applied to a familiar house situated in Texas (US). Figure 5a shows that the selfshading façade has higher environmental impact than a conventional façade with equal structural and thermal performance. In particular, the 10\% extra brick needed for the self-shading function is the largest contributor to the difference in impact. Similarly, after 50 years of operation, the self-shading façade continues having higher contributions. However, in this case, the difference between the relative impacts of the two walls decreases (see Figure $\mathbf{5 b}$ ). The results confirmed the high influence of the production phase in the global impact of a building element.
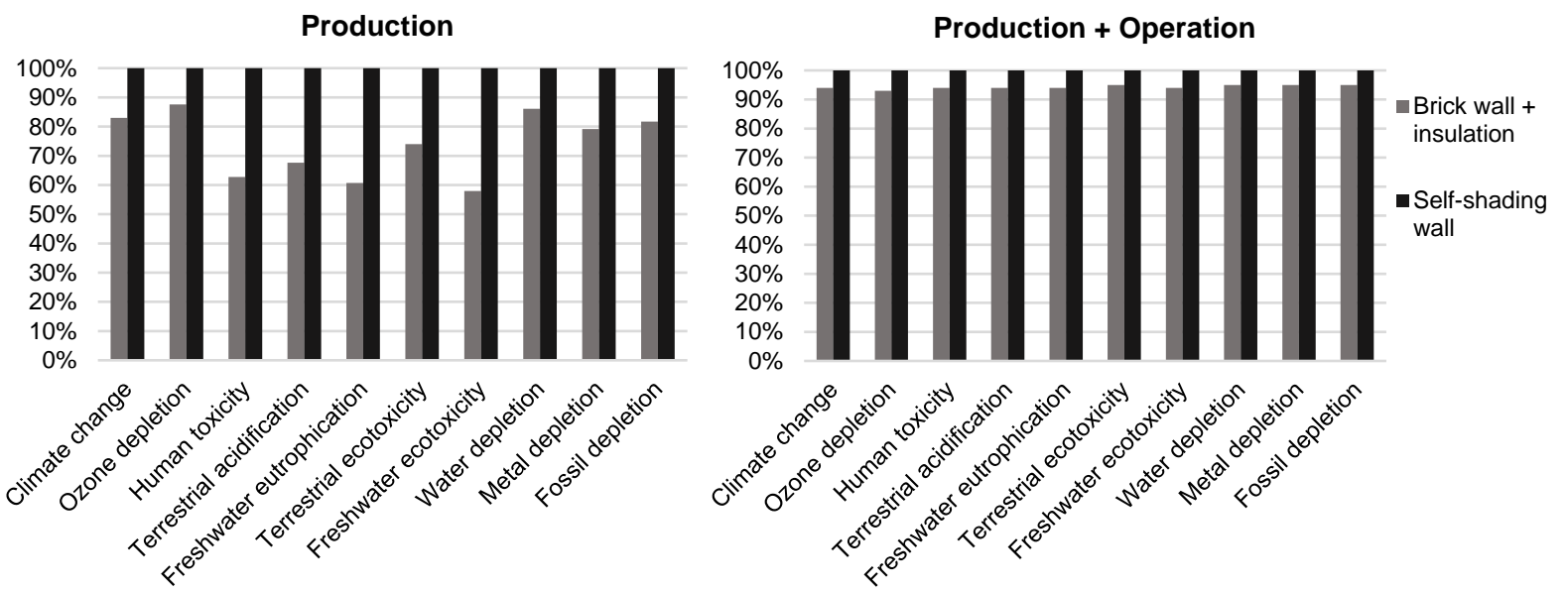

Figure 5. (a) Relative contribution of the wall production process to the impact categories. (b) Relative contribution of the wall production and operation phases to the impact categories.

\subsubsection{Sensitivity analysis}

Given the previous results, a sensitivity analysis of the environmental performance in relation to material usage was essential to study the possibilities of achieving lower environmental impacts than 
conventional construction. The high impact of the brick production process on the life cycle of the digital fabrication façade highlighted the need for a reduction in the additional amount of brick used to create the self-shading effect. Figure 6 graphically depicts how the $\mathrm{CO}_{2}$ emissions during production and operation decrease proportionally to the reduction of brick used for self-shading. The study of the production process presented by S. Andreani and M. Bechthold indicated that the minimum cutting angle to create shading effect on the bricks was $8^{\circ}$ (Gramazio et al., 2014). At this angle, only $3 \%$ additional brick was required for the digitally fabricated façade. Therefore, an optimized design would bring an improvement on the environmental performance of the self-shading brick façade. However, even reducing the structural capacity of the self-shading wall to achieve the same amount of brick as in the conventional system, the $\mathrm{CO}_{2}$ emissions are still higher (194.73 $\mathrm{kg} \mathrm{CO}_{2}$ eq.).

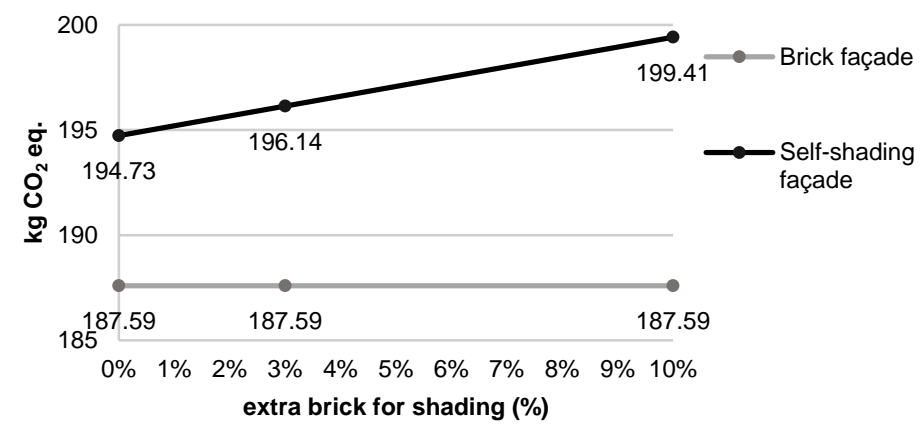

Figure 6. Climate change impacts of the wall systems during production and operation, depending on the $\%$ of extra brick considered for the self-shading façade.

Despite the preceding material sensitivity analysis, we conducted a further study on the production process of both walls to determine if possible environmental benefits could be achieved with the optimization of the digital fabrication process. For this assessment, we considered that the self-shading wall had a minimum $3 \%$ additional brick to create the thermal function and conserve the same structural performance as the conventional wall. Figure 7 shows the results of the comparison of $\mathrm{CO}_{2}$ emissions associated with the production of the digitally fabricated and the conventional wall. We observe that the digital fabrication process is responsible for $7.92 \mathrm{~kg} \mathrm{CO}_{2}$ eq. and the additional $3 \%$ brick for $1.4 \mathrm{~kg} \mathrm{CO} 2$ eq. Simultaneously, the graph shows that the environmental impact of the EPS insulation is only 0.83 $\mathrm{kg} \mathrm{CO}_{2}$ eq. Therefore, the thermal function in the conventional system has a low environmental impact that cannot compensate the impact of the self-shading production. As a result, in this case study digital fabrication did not provide environmental benefits.

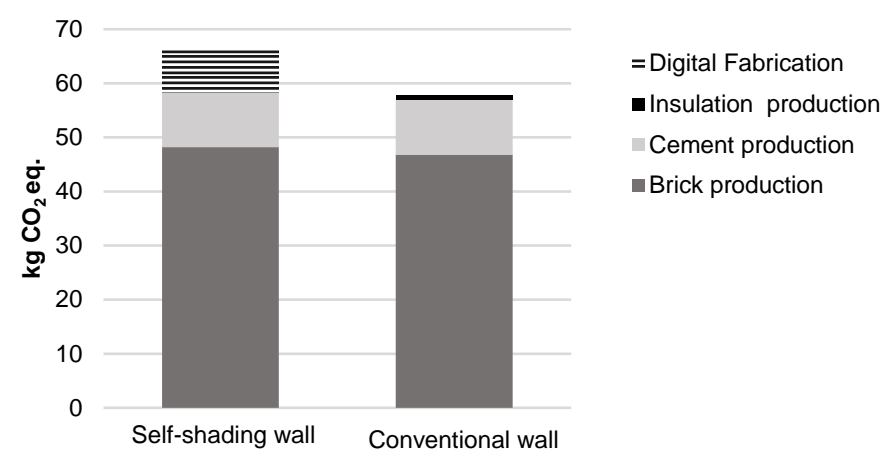


Figure 7. Relative contribution of each process involved in the self-shading and conventional system production to climate change impact.

\subsection{Floor}

\subsubsection{Environmental impact of the digital fabrication project}

The ultra-thin concrete structure without reinforcing bars is composed of high-performance, selfcompacting, fibre-reinforced concrete (SCFRC) with special properties. Figure 8 graphically depicts the comparison of $\mathrm{CO}_{2}$ emissions derived from the production of $1 \mathrm{~m}^{3}$ of SCFRC and the same volume of a ready mix concrete with CEM I 42.5. The graph shows that the impact of high-performance concrete production is greater than conventional concrete. This impact can be attributed to the use of approximately three times the standard amount of cement per $\mathrm{m}^{3}$ in the composition of the SCFRC (see Table 3). Simultaneously, Figure 9 shows the comparison of climate change emissions related to the functional unit of the case study ( $1 \mathrm{~m}^{2}$ of both floor systems). This analysis establishes that the $\mathrm{CO}_{2}$ emissions of the computationally designed vault are 50\% lower than the conventional floor. Published literature related to the environmental analysis of ultra-high performance fibre-reinforced concrete presented similar results. Due to the difference between the two solutions at the cubic metre scale, $a$ much lower volume is needed in the project with SCFRC. Moreover, high-performance concrete has a higher durability than traditional concrete (Habert et al., 2013). Therefore, the results highlighted the environmental benefits of concrete optimization in architecture.

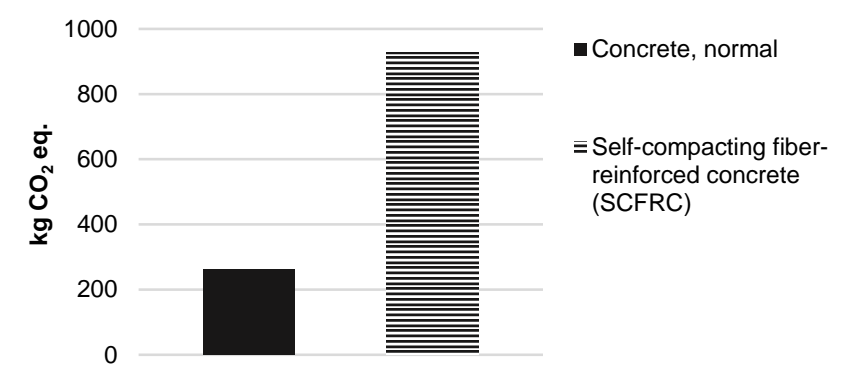

Figure 8. Relative contribution to the climate change category of $1 \mathrm{~m}^{3}$ of SCFRC and $1 \mathrm{~m}^{3}$ of concrete, normal, at plant.

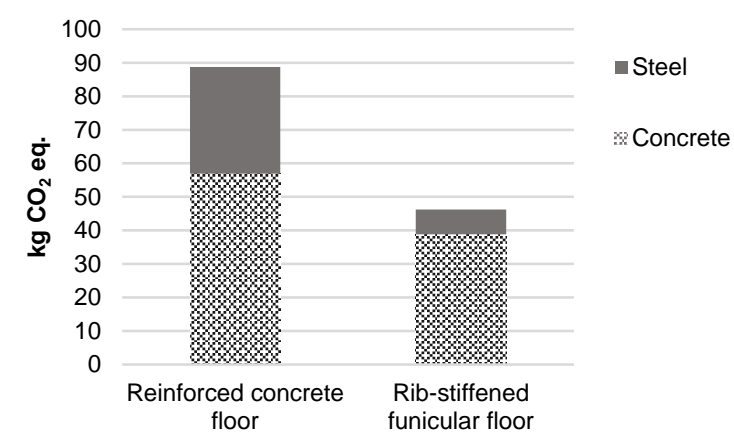

Figure 9. Relative contribution to the climate change category of $1 \mathrm{~m}^{2}$ of the "Rib-stiffened funicular floor system" and $1 \mathrm{~m}^{2}$ of a conventional reinforced concrete floor. 
The results of the comparison indicated that the concrete vaulted floor system had approximately $75 \%$ less self-weight than a $22 \mathrm{~cm}$ bidirectional concrete slab floor. The concrete vaulting within the slab system reduced concrete consumption by $32 \%$ per $\mathrm{m}^{2}$ and reduced steel consumption by $76 \%$ per $\mathrm{m}^{2}$. Furthermore, the use of lightweight vaults as floor structures may considerably reduce the load and material requirements in building supports and foundations. Figure 10 shows the environmental comparison of the "Rib-stiffened funicular floor system" and a conventional concrete slab. The analysis shows that the relative contribution of the ultra-thin vaulted structure to the environmental impact is approximately 50\% lower than the reinforced slab. Particularly, the impact of the vaulted floor to metal depletion is less than $25 \%$ due to the elimination of steel reinforcement and its replacement by steel fibres in the concrete.

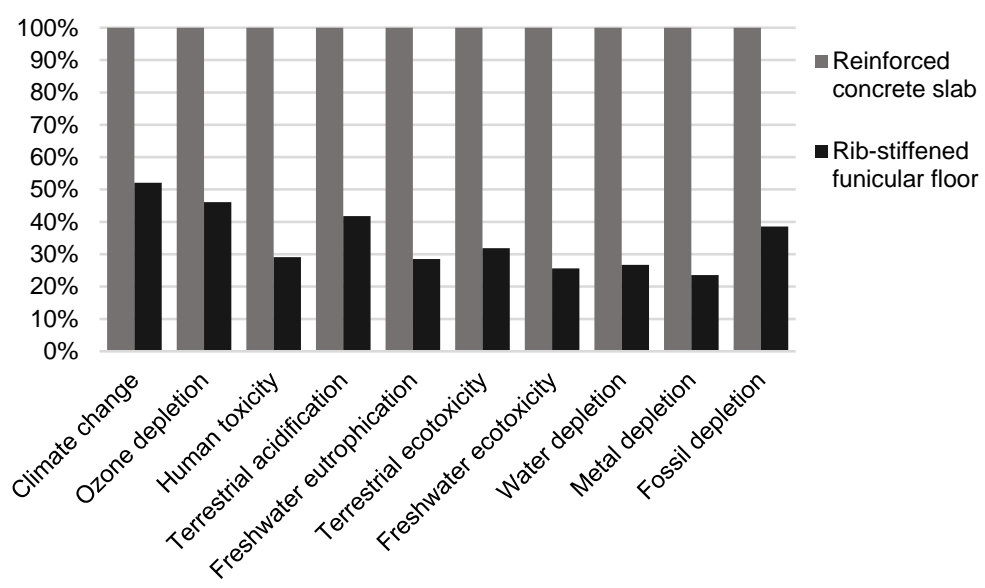

Figure 10. Comparison of the environmental impacts of $1 \mathrm{~m}^{2}$ of the "Rib-stiffened funicular floor system" and a conventional reinforced concrete slab.

This case study demonstrated the advantages of a performative computational design for efficient material consumption in high-performance structural applications. Through computational structural optimization, digital fabrication can reduce the amount of highly industrialized materials such as steel or concrete, gaining significant environmental benefits.

\subsection{Roof}

\subsubsection{Environmental impact of the digital fabrication project}

The results from the environmental assessment were broken down into four processes: spruce timber production, low-alloyed steel production, digital fabrication technologies (construction robot and desktop computer) production and electricity consumed during construction. Figure $\mathbf{1 1}$ describes the relative contribution of each process to the overall environmental impact of "The Sequential Roof" construction. The results indicate that more than $95 \%$ of the environmental impact associated with the robotically fabricated roof is caused by materials production. Specifically, timber production has a relative contribution of approximately $70 \%$ to the overall impact in most of the midpoint categories. However, in 
metal depletion, steel production has the largest contribution. Simultaneously, the graph shows that the energy consumption during construction has a relative impact lower than $10 \%$ in all the indicators. The direct impacts of the electricity use are low because the production process in Switzerland, where the electricity generation mix is made by $55 \%$ hydropower, $40 \%$ nuclear, $4 \%$ biofuels and waste and only 2\% natural gas (International Energy Agency, 2012). Similarly, the relative impact of the production of digital fabrication technologies is less than $2 \%$ in all midpoint categories. In conclusion, the analysis proved that the impact of digital fabrication is negligible compared to the impact of the timber and steel manufacturing processes.

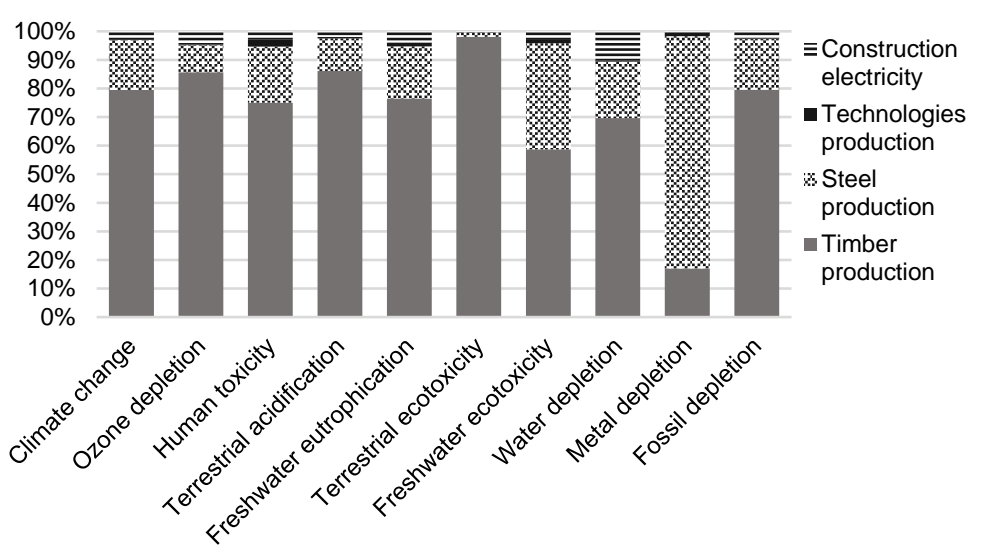

Figure 11. Relative contribution of each process to the total environmental impact of the production of 1 $\mathrm{m}^{2}$ of "The Sequential Roof".

\subsubsection{Comparative LCA with conventional construction}

We compared the life cycle of the digitally fabricated roof structure with a conventional wood roof system composed of a roof structure and hanging ceiling. Figure 12 graphically depicts the environmental impacts of both production processes. "The Sequential Roof" production shows clear environmental benefits. Specifically, the difference between the environmental impacts of the construction systems is between 30 and $40 \%$ in all categories. For example, in climate change, the $\mathrm{CO}_{2}$ emissions of "The Sequential Roof" are more than $40 \%$ lower than the conventional roof.

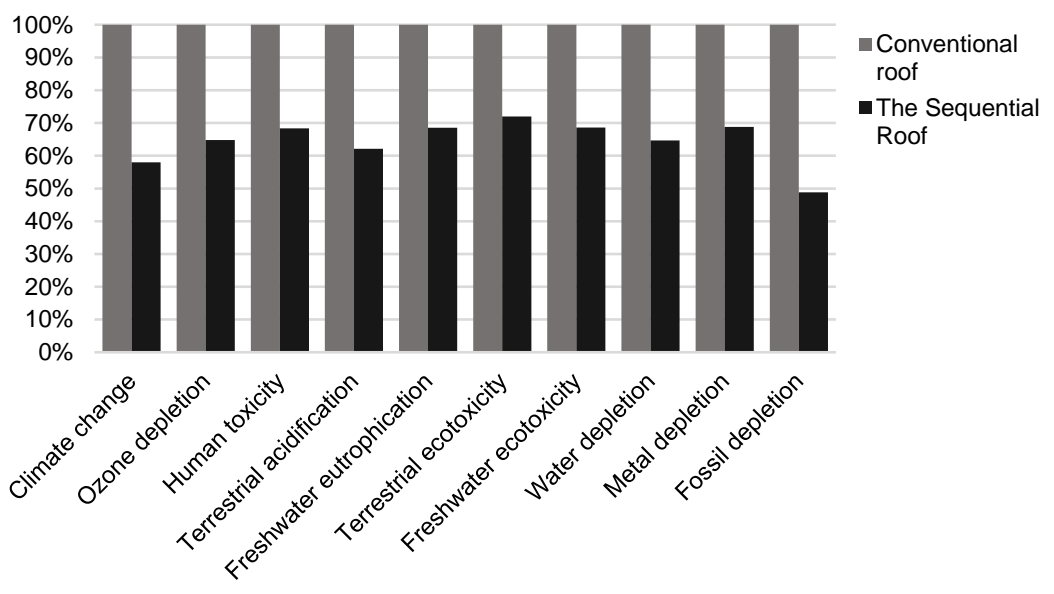


Figure 12. Comparison of the environmental impacts of $1 \mathrm{~m}^{2}$ of "The Sequential Roof" and a conventional roof structure.

This case study demonstrated the advantages of a computational design and robotic assembly of small elements for the creation of structural elements. Additionally, the combination of different functions in a single element allowed for a more efficient and material-efficient construction process. Through digital fabrication, significant performance, economic and environmental benefits were gained.

\subsubsection{Sensitivity analysis}

During the definition of the functional unit, a hanging ceiling with insulation was added to the conventional roof structure to achieve the acoustic and finishing functions integrated in the structure of "The Sequential Roof". Figure $\mathbf{1 3}$ classifies the overall environmental impact of the conventional roof in the two production processes. Specifically, we observe that the hanging ceiling panel has high contributions to most of the environmental impact categories. Therefore, the variability of its composition may alter the comparative results.

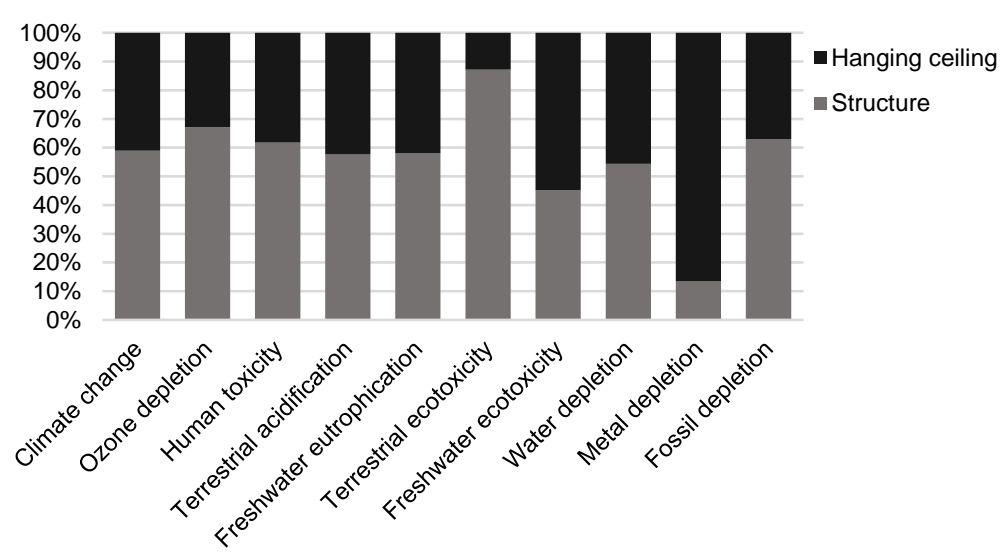

Figure 13. Relative contribution of each process to the total environmental impact of the production of 1 $\mathrm{m}^{2}$ of conventional wood roof.

To evaluate the variability of the results depending on the constructive solution, the projects were compared by adopting different hanging ceiling solutions in the conventional roof. Originally, the ceiling typology was composed of a steel structure, rock wool insulation and laminated wood. We introduced a variation on the materiality and thickness of the last two. For the indoor layer, two solutions were assessed: $16 \mathrm{~mm}$ laminated wood and $12 \mathrm{~mm}$ plywood. The materiality of the insulation layer varied between rock wool, glass wool and cellulose fibre in 4 different thicknesses between 40 and $100 \mathrm{~mm}$. In total, 24 additional solutions were considered for the conventional roof and were compared with the environmental impact of "The Sequential Roof" (see supplementary information).

The impacts of "The Sequential Roof" were lower in all midpoint categories. Figure 14 shows the variability of the environmental impacts of the conventional roof and their difference with the digitally 
fabricated roof. Most of the impacts of the conventional roof are approximately 50\% higher than "The Sequential Roof". However, in fossil depletion, the impact of the conventional roof duplicates the digitally fabricated roof due to the larger use of resources during materials production. Simultaneously, the variability of the impacts depending on the hanging ceiling solution has a small influence on the results. In terrestrial ecotoxicity, the standard deviation is $43 \%$ due to the higher impact of the plywood panel solution. However, considering the worst scenario, the environmental impact of the conventional roof is $40 \%$ larger. Therefore, the variability of the hanging ceiling composition has a negligible effect on the comparison.

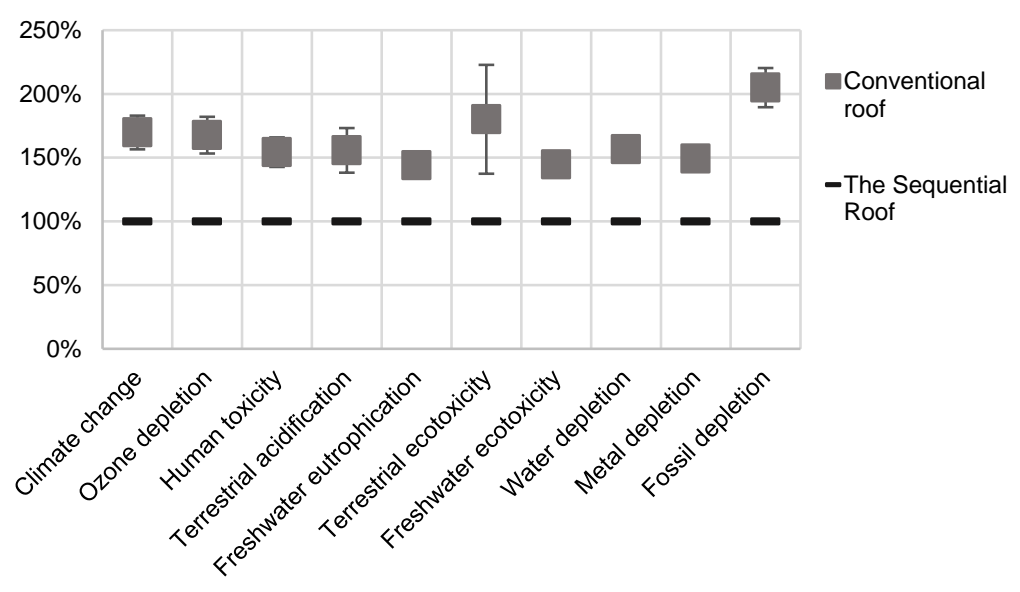

Figure 14. Comparison between "The Sequential Roof" and conventional roof for different environmental impact categories. Error bars represent the standard deviation of the impacts, depending on the hanging ceiling solution considered.

\section{Synthesis and Guidelines}

Following the key parameters identified from the previous results are presented and discussed.

\subsection{Environmental impact of digital fabrication process is negligible}

The results of the evaluation indicated that the energy and resource consumption of the robotic fabrication processes contributed minimally in terms of energy and environmental impacts. The first and third case studies highlighted the low relative impact of digital fabrication compared with materials production. Specifically, the production of digital fabrication technologies had a negligible impact on all midpoint categories from both case studies. Additionally, the relative contribution to environmental impacts of the robotic construction process was low, especially in the roof analysis, because of the Swiss electricity mix. As several studies have proven, the construction phase (including the use of temporary materials and equipment on-site) has a very small contribution to the life cycle impacts of a building. For example, Hong et al. (2014) stated that direct emissions derived from on-site construction were small (2.42\%) compared to the indirect emissions embedded in the production of building materials (97.58\%). Junnila et al. (2006) presented similar results, where the materials production accounted for $10 \%$ of the energy consumption and $\mathrm{CO}_{2}$ emissions, whereas the construction phase had an environmental impact of approximately $1.5 \%$ compared to the overall life cycle emissions. Moreover, related literature, such 
as Mao et al. (2013) and Wen et al. (2015), demonstrated that GHG emissions derived from the construction phase were even more reduced in prefabricated processes.

In this research, we focused on the additional impacts induced by the use of digital fabrication and we showed that these additional impacts were also negligible. The environmental impact of the construction phase was reduced to the electricity consumption by a robot and a computer during construction. The case studies were simplified assuming that the impacts of conventional use of temporary materials and equipment on-site were equal and negligible in both architectural elements compared, and therefore, were excluded from the LCA comparison. Generally, the use of digital fabrication technologies does not exclude additional on-site construction processes, such as equipment or transport, which are typically used in conventional construction. Instead, robotic fabrication processes are used to avoid manual construction of specific customized structures, which would require long construction times and specialized labour due to their high formal complexity. A common argument against the use of digital fabrication is the increase of energy consumption in construction, which derives in environmental emissions. However, this study demonstrated that material optimization should be the focus of designers to achieve environmental benefits in digital fabrication.

\subsection{Digital fabrication allows the integration of additional functions in the structure}

We observed that in many projects, digital fabrication allows the integration of additional functions in the structure. This integrated performance provides added value to architecture and potential material savings. However, in some architectural projects, additional functions can increase the requirement of material for the primary function, which might be disadvantageous from an environmental point of view. The first case study showed environmental disadvantages in the use of the digital fabrication processes during the production of brick façades. An important factor in the comparison was the additional thermal function represented by the self-shading effect and compared with the insulation in the conventional system. The analysis showed that the EPS insulation had a small influence on the global environmental impact of the wall compared to the additional brick and digital fabrication process needed for the creation of a self-shading effect. Therefore, the integration of an additional thermal function in the structure did not provide environmental benefits because the equivalent function in the conventional wall had a low environmental impact.

In contrast, the third case study demonstrated the advantages of integrating additional functions with high environmental impact in the structure. Specifically, the results showed that the hanging ceiling was responsible for approximately $40 \%$ of the impact. Therefore, the integration of finishing and acoustic functions in the roof structure allowed a material-reductive construction process, beneficial from an environmental point of view. In conclusion, the integration of additional functions in digitally fabricated structures only provided environmental benefits when the equivalent function in the conventional system had a high environmental impact. Consequently, in digitally fabricated projects, the integration of additional functions in the structure can compensate a higher material requirement for the structural performance of the building element. 
The manufacture of building materials represents $5-10 \%$ of the global $\mathrm{CO}_{2}$ emissions (Habert et al., 2012). Within this sector, cement and steel are the main contributors to high primary energy demands and $\mathrm{CO}_{2}$ emissions (Zabalza Bribián et al., 2011). The environmental impact of a project depends greatly on the choice of materials and adequate optimization of material usage during design. By integrating digital technologies and new insights from material science, conventional techniques are modified to create material-reducing approaches that contribute to the reduction of environmental impacts. Innovative computational approaches integrate structural form-finding in design, offering new possibilities of formal expression and addressing resource efficiency in architecture (Rippmann and Block, 2013). The second case study demonstrated the advantages of performative computational design to control material consumption in high performance structural applications. Through computational structural optimisation and by using high performance fibre reinforced concrete, a significant reduction of material was achieved. This reduction of concrete and reinforcing steel, compared to a conventional structure with the same function, reduced environmental impact. In conclusion, digital fabrication can reduce the amount of highly industrialized materials (high environmental impact) through form finding optimization.

The end of life of structures is rarely the phase that contributes the most to environmental impacts (Blengini and Di Carlo, 2010), except when a waste impact category is used in the method, which is not the majority of the impact calculation methods (Lasvaux et al., 2016). Furthermore, digital fabrication will provide similar results as conventional fabrication because it uses the same materials, therefore, the demolition process and recycling will not be different. However, there might still be pollution transfer between impact categories. For instance, considering the brick wall, the additional inert waste generated at the end of life of the shaded wall has to be balanced with the energy (electricity) reduction that occurred during the operation of the building. Those two processes are affecting different impact categories, and therefore, a decision will have to be madeby selecting which impact category is the most important. Note that it could also be assessed through a land use impact category balancing the square metres of landfill used by the brick compared to the square metres saved in terms of renewable energy (Hertwich et al., 2015). Considering "The Sequential Roof", the additional wood used for the structure could improve the existing comparison between the digitally fabricated and conventional structure. Actually, if the avoided impact linked with the use of wood as a heating source to avoid electricity or fossil fuel is considered, the digitally fabricated roof will be even better than a conventional wooden roof using glue laminated beams, which cannot be easily burnt. As a conclusion, for the three specific cases studied, considering the end of life will not drastically change the results, but it would increase the level of the hypothesis, which is already quite high due to the difficulty of the definition of the functional unit. The end of life scenario will be added to the uncertainty without being sure (at least for those three case study) that it has a strong influence. 
techniques is the addition of robots and computers on the construction site. These innovative building technologies increase the demand of metal consumption, leading to a concern about resources depletion and supply risks (Robinson, 2009). For instance, the replacement of CRT monitors with LCD displays reduces lead demand but increases the use of mercury, indium, tin and zinc (ITU, 2012). The use of rare earth elements in electronics has grown rapidly in recent years. These metals are sometimes mined in a limited number of countries (e.g., China or Japan) at long distances from the main importers. Consequently, metals become vulnerable to potential supply restrictions resulting from natural disasters, regulation and trade issues, leading to concerns about supply risks and economic consequences (Nansai et al., 2014). However, other industrial sectors consume more rare materials than digital fabrication, for instance the manufacturing of low carbon technologies. Therefore, technologies employed in the construction sector, such as solar panels, have higher criticality risk than digital fabrication technologies (Roelich et al., 2014). The potential consequences of this extra metal requirement should be evaluated considering the full socio-economic system without reducing the study to the project level. Other methods could be used, such as hybrid LCA and criticality assessment, but this analysis is beyond the scope of this study.

\section{Conclusion}

In this study, we analysed three different case studies using digital fabrication as an innovative construction process. The case studies represented three typical construction elements, and each was compared to the conventional building element with a similar function. From the LCA results, criteria to consider during design were identified and discussed. The goal of these criteria is to develop a better understanding of digital processes at the building scale, establishing the knowledge base for the development of environmental guidelines to help designers make better-informed and more sustainable choices in the implementation of digital fabrication.

One of the main conclusions extracted from the analysis was that the impact of digital fabrication processes was negligible compared to the materials manufacturing process. This means that any digital fabrication project that can save materials compared to conventional construction will allow for reduction of environmental impacts. Furthermore, the study highlighted the opportunities for integrating additional functions in digitally fabricated structures to reduce the overall environmental impact of these multifunctional elements. However, the integration of multiple functions allows great savings only when these functions have a large environmental impact. This is the case for two out three of the studied projects. Finally, the second case study demonstrated that digital fabrication can reduce the amount of highly industrialized materials. An important reduction on environmental impacts was achieved through computational structural optimization.

\section{Acknowledgements}

The authors thank the Institute of Structural Engineering (IBK) from the ETH Zürich for their invaluable help in the calculation of the conventional structures. This research was supported by the National Competence Centre for Research, NCCR Digital Fabrication, funded by the Swiss National Science 
Foundation (project number 51NF40_141853).

\section{References}

Andreani, S., Bechthold, M., 2014. [R]EVOLVING BRICK: Geometry and performance innovation in ceramic building systems through design robotics, in: Gramazio, F., Kohler, M., Langenberg, S. (Eds.), FABRICATE: NEGOTIATING DESIGN \& MAKING. gta Verlag, ETH Zurich, Zurich, Switzerland, pp. 182-191.

Andreani, S., Bechthold, M., del Castillo, J., Jyoti, A., King, N., 2012. Flowing matter: Robotic fabrication of complex ceramic systems, Proceedings of ISG* ISARC2012-International Symposium on Automation.

Azhar, S., Brown, J., 2009. BIM for sustainability analyses. International Journal of Construction Education and Research 5, 276-292.

Bates, R., Carlisle, S., Faircloth, B., Welch, R., 2013. Quantifying the Embodied Environmental Impact of Building Materials During Design: A Building Information Modeling Based Methodology. PLEA. Munich, 1-6.

Blengini, G.A., Di Carlo, T., 2010. The changing role of life cycle phases, subsystems and materials in the LCA of low energy buildings. Energy and Buildings 42, 869-880.

Bovea, M.D., Ibáñez-Forés, V., Agustí-Juan, I., 2014. 7 - Environmental product declaration (EPD) labelling of construction and building materials, Eco-efficient Construction and Building Materials. Woodhead Publishing, pp. 125-150.

Cabeza, L.F., Rincón, L., Vilariño, V., Pérez, G., Castell, A., 2014. Life cycle assessment (LCA) and life cycle energy analysis (LCEA) of buildings and the building sector: A review. Renewable and Sustainable Energy Reviews 29, 394-416.

Chen, C., Habert, G., Bouzidi, Y., Jullien, A., Ventura, A., 2010. LCA allocation procedure used as an incitative method for waste recycling: an application to mineral additions in concrete. Resources, Conservation and Recycling 54, 1231-1240.

Chen, D., Heyer, S., Ibbotson, S., Salonitis, K., Steingrímsson, J.G., Thiede, S., 2015. Direct digital manufacturing: definition, evolution, and sustainability implications. Journal of Cleaner Production 107, 615-625.

Czmoch, I., Pękala, A., 2014. Traditional Design versus BIM Based Design. Procedia Engineering 91, 210-215.

Damineli, B.L., Kemeid, F.M., Aguiar, P.S., John, V.M., 2010. Measuring the eco-efficiency of cement use. Cement and Concrete Composites 32, 555-562.

Deng, L., Babbitt, C.W., Williams, E.D., 2011. Economic-balance hybrid LCA extended with uncertainty analysis: case study of a laptop computer. Journal of Cleaner Production 19, 1198-1206.

Ding, G.K.C., 2014. 3 - Life cycle assessment (LCA) of sustainable building materials: an overview, Eco- 
efficient Construction and Building Materials. Woodhead Publishing, pp. 38-62.

Dunn, N., 2012. Digital fabrication in architecture. Laurence King Publishing Ltd, London.

European Parliament and Council, 2010. Directive 2010/31/EU of the European Parliament and of the Council of 19 May 2010 on the energy performance of buildings (recast). Official Journal of the European Union 18, 2010.

Faludi, J., Bayley, C., Bhogal, S., Iribarne, M., 2015. Comparing environmental impacts of additive manufacturing vs traditional machining via life-cycle assessment. Rapid Prototyping Journal 21, 14-33.

Fava, J.A., 2006. Will the next 10 years be as productive in advancing life cycle approaches as the last 15 years? The International Journal of Life Cycle Assessment 11, 6-8.

Gebler, M., Uiterkamp, A.J.S., Visser, C., 2014. A global sustainability perspective on 3D printing technologies. Energy Policy 74, 158-167.

Gershenfeld, N., 2012. How to make almost anything: The digital fabrication revolution. Foreign Affairs 91, 43-57.

Goedkoop, M., Heijungs, R., Huijbregts, M., De Schryver, A., Struijs, J., van Zelm, R., 2009. ReCiPe 2008: A life cycle impact assessment method which comprises harmonised category indicators at the midpoint and the endpoint level. Ministry of Housing, Spatial Planning and Environment (VROM), Den Haag.

Government of South Australia, 2015. Insulation, ventilation and draught proofing your home. https://www.sa.gov.aul (accessed 23.04.2015).

Gramazio, F., Kohler, M., 2008. Digital materiality in architecture. Lars Müller Publishers, Baden.

Gramazio, F., Kohler, M., Langenberg, S., 2014. FABRICATE: Negotiating Design \& Making. gta Verlag, Zurich.

Gramazio Kohler Research, 2014. The Sequential Roof. http://gramaziokohler.arch.ethz.ch/web/e/forschung/201.html (accessed 27/08/2015).

Habert, G., Arribe, D., Dehove, T., Espinasse, L., Le Roy, R., 2012. Reducing environmental impact by increasing the strength of concrete: quantification of the improvement to concrete bridges. Journal of Cleaner Production 35, 250-262.

Habert, G., Denarié, E., Šajna, A., Rossi, P., 2013. Lowering the global warming impact of bridge rehabilitations by using Ultra High Performance Fibre Reinforced Concretes. Cement and Concrete Composites 38, 1-11.

Hack, N., Lauer, W.V., 2014. Mesh-Mould: Robotically Fabricated Spatial Meshes as Reinforced Concrete Formwork. Architectural Design 84, 44-53.

Hague, R., Campbell, I., Dickens, P., 2003. Implications on design of rapid manufacturing. Proceedings of the Institution of Mechanical Engineers, Part C: Journal of Mechanical Engineering Science 217, 2530 .

Hertwich, E.G., Gibon, T., Bouman, E.A., Arvesen, A., Suh, S., Heath, G.A., Bergesen, J.D., Ramirez, 
A., Vega, M.I., Shi, L., 2015. Integrated life-cycle assessment of electricity-supply scenarios confirms global environmental benefit of low-carbon technologies. Proceedings of the National Academy of Sciences 112, 6277-6282.

Hischier, R., Weidema, B., Althaus, H.-J., Bauer, C., Doka, G., Dones, R., Frischknecht, R., Hellweg, S., Humbert, S., Jungbluth, N., Köllner, T., Loerincik, Y., Margni, M., Nemecek, T., 2010. Implementation of Life Cycle Impact Assessment Methods. Final report ecoinvent v2.2 No. 3. Swiss Centre for Life Cycle Inventories, Dübendorf.

Hollberg, A., Ruth, J., 2016. LCA in architectural design-a parametric approach. The International Journal of Life Cycle Assessment 21, 943-960.

Hong, J., Shen, G.Q., Feng, Y., Lau, W.S.-t., Mao, C., 2014. Greenhouse gas emissions during the construction phase of a building: a case study in China. Journal of Cleaner Production 103, 249-259. IHOBE, 2010. GUIDE BOOKS ON ECODESIGN. CONSTRUCTION MATERIAL, Bilbao.

Ingrao, C., Scrucca, F., Tricase, C., Asdrubali, F., 2016. A comparative Life Cycle Assessment of external wall-compositions for cleaner construction solutions in buildings. Journal of Cleaner Production 124, 283-298.

International Energy Agency, 2012. Energy Policies of IEA Countries - Switzerland, Paris.

Ioannidou, D., Zerbi, S., Habert, G., 2014. When more is better - Comparative LCA of wall systems with stone. Building and Environment 82, 628-639.

ISO, 2006a. 14040: Environmental management-life cycle assessment-principles and framework.

ISO, 2006b. 14044: Environmental management—life cycle assessment—requirements and guidelines. International Organization for Standardization.

ITU, 2012. End of Life Management for ICT Equipment, in: ITU (Ed.), Toolkit on Environmental Sustainability for the ICT sector (ESS).

Junnila, S., Horvath, A., Guggemos, A.A., 2006. Life-cycle assessment of office buildings in Europe and the United States. Journal of Infrastructure Systems 12, 10-17.

King, N., Bechthold, M., Kane, A., Michalatos, P., 2014. Robotic tile placement: Tools, techniques and feasibility. Automation in Construction 39, 161-166.

Kohtala, C., Hyysalo, S., 2015. Anticipated environmental sustainability of personal fabrication. Journal of Cleaner Production 99, 333-344.

Kreiger, M., Pearce, J.M., 2013. Environmental life cycle analysis of distributed three-dimensional printing and conventional manufacturing of polymer products. ACS Sustainable Chemistry \& Engineering 1, 1511-1519.

Lasvaux, S., Achim, F., Garat, P., Peuportier, B., Chevalier, J., Habert, G., 2016. Correlations in Life Cycle Impact Assessment methods (LCIA) and indicators for construction materials: What matters? Ecological Indicators 67, 174-182.

Lim, S., Buswell, R.A., Le, T.T., Austin, S.A., Gibb, A.G., Thorpe, T., 2012. Developments in 
construction-scale additive manufacturing processes. Automation in construction 21, 262-268.

Lloret, E., Shahab, A.R., Linus, M., Flatt, R.J., Gramazio, F., Kohler, M., Langenberg, S., 2014. Complex concrete structures: Merging existing casting techniques with digital fabrication. Computer-Aided Design $60,40-49$.

López López, D., Veenendaala, D., Akbarzadeha, M., Block, P., 2014. Prototype of an ultra-thin, concrete vaulted floor system, Proceedings of the IASS-SLTE 2014 Symposium.

Malé-Alemany, M., Portell, J., 2014. FABbots: Research in additive manufacturing for architecture, in: Gramazio, F., Kohler, M., Langenberg, S. (Eds.), FABRICATE: NEGOTIATING DESIGN \& MAKING. gta Verlag, Zurich, pp. 206-215.

Mao, C., Shen, Q., Shen, L., Tang, L., 2013. Comparative study of greenhouse gas emissions between off-site prefabrication and conventional construction methods: two case studies of residential projects. Energy and Buildings 66, 165-176.

Moussavi, F., Kubo, M., Hoffman, S., 2006. The function of ornament. Actar, Barcelona.

Nansai, K., Nakajima, K., Kagawa, S., Kondo, Y., Suh, S., Shigetomi, Y., Oshita, Y., 2014. Global flows of critical metals necessary for low-carbon technologies: the case of neodymium, cobalt, and platinum. Environmental science \& technology 48, 1391-1400.

Nemry, F., Uihlein, A., 2008. Environmental improvement potentials of residential buildings (IMPRObuilding). JRC, European Commission

Nielsen, P.H., Wenzel, H., 2002. Integration of environmental aspects in product development: a stepwise procedure based on quantitative life cycle assessment. Journal of Cleaner Production 10, 247257.

Ortiz, O., Castells, F., Sonnemann, G., 2009. Sustainability in the construction industry: A review of recent developments based on LCA. Construction and Building Materials 23, 28-39.

Passer, A., Kreiner, H., Maydl, P., 2012. Assessment of the environmental performance of buildings: A critical evaluation of the influence of technical building equipment on residential buildings. The International Journal of Life Cycle Assessment 17, 1116-1130.

Pearce, J.M., Blair, C.M., Laciak, K.J., Andrews, R., Nosrat, A., Zelenika-Zovko, I., 2010. 3-D printing of open source appropriate technologies for self-directed sustainable development. Journal of Sustainable Development 3, 17-29.

Purnell, P., Black, L., 2012. Embodied carbon dioxide in concrete: Variation with common mix design parameters. Cement and Concrete Research 42, 874-877.

Rippmann, M., Block, P., 2013. Rethinking structural masonry: unreinforced, stone-cut shells. Proceedings of the ICE-Construction Materials 166, 378-389.

Robinson, B.H., 2009. E-waste: an assessment of global production and environmental impacts. Science of the total environment $408,183-191$.

Roelich, K., Dawson, D.A., Purnell, P., Knoeri, C., Revell, R., Busch, J., Steinberger, J.K., 2014. 
Assessing the dynamic material criticality of infrastructure transitions: A case of low carbon electricity. Applied Energy 123, 378-386.

Shah, V.P., Debella, D.C., Ries, R.J., 2008. Life cycle assessment of residential heating and cooling systems in four regions in the United States. Energy and Buildings 40, 503-513.

UNEP, 2012. Building Design and Construction: Forging Resource Efficiency and Sustainable Development.

Weidema B. P., B.C., Hischier R., Mutel C., Nemecek T., Reinhard J., Vadenbo C. O., Wernet G., 2013. Overview and methodology. Data quality guideline for the ecoinvent database version 3, Ecoinvent Report 1(v3). The ecoinvent Centre, St. Gallen.

Wen, T.J., Siong, H.C., Noor, Z., 2015. Assessment of embodied energy and global warming potential of building construction using life cycle analysis approach: Case studies of residential buildings in Iskandar Malaysia. Energy and Buildings 93, 295-302.

Williams, E.D., Sasaki, Y., 2003. Energy analysis of end-of-life options for personal computers: resell, upgrade, recycle, Electronics and the Environment, 2003. IEEE International Symposium on. IEEE, pp. 187-192.

Willmann, J., Knauss, M., Bonwetsch, T., Apolinarska, A.A., Gramazio, F., Kohler, M., 2016. Robotic timber construction-Expanding additive fabrication to new dimensions. Automation in Construction 61, 16-23.

Wong, K.-d., Fan, Q., 2013. Building information modelling (BIM) for sustainable building design. Facilities 31, 138-157.

Zabalza Bribián, I., Valero Capilla, A., Aranda Usón, A., 2011. Life cycle assessment of building materials: Comparative analysis of energy and environmental impacts and evaluation of the ecoefficiency improvement potential. Building and Environment 46, 1133-1140.

Zhang, T.W., Dornfeld, D.A., 2007. Energy use per worker-hour: Evaluating the contribution of labor to manufacturing energy use, Advances in Life Cycle Engineering for Sustainable Manufacturing Businesses. Springer, pp. 189-193. 